\title{
Updated Oxford classification of IgA nephropathy: expanding scope of the schema
}

\author{
Muhammed Mubarak ${ }^{*}$ \\ Histopathology Department, Sindh Institute of Urology and Transplantation, Karachi, Pakistan
}

\section{A R T I C L E I N F O}

\section{Article Type:}

Editorial

\section{Article History:}

Received: 11 January 2018

Accepted: 3 February 2018

Published online: 12 February 2018

\section{Keywords:}

IgA nephropathy

MEST scores

Oxford classification

Crescents

MEST classification
Implication for health policy/practice/research/medical education:

With the incorporation of crescents (C) score to all cases of IgAN to indicate the frequency of cellular and/or fibrocellular crescents as C0 (no crescents), C1 (crescents in 1 to 24\% glomeruli) or C2 (cresents in $\geq 25 \%$ glomeruli), subdivision of the $\mathrm{S}$ lesion (podocytopathic or non-podocytopathic in origin) and integration of the clinical data at the time of biopsy with MEST (Oxford classification) classification, the updated Oxford classification aims to further enhance the prognostic power of the classification. As a result, the updated Oxford classification now includes 5 instead of 4 pathological parameters, i.e., MEST-C score.

Please cite this paper as: Mubarak M. Updated Oxford classification of IgA nephropathy: expanding scope of the schema. J Renal Inj Prev. 2018;7(2):53-55. DOI: 10.15171/jrip.2018.13.
$\mathrm{I}$ gA nephropathy (IgAN) is the most common glomerulopathy worldwide with divergent incidence and prevalence rates, chiefly reflecting different biopsy practices in different parts of the world. It is a heterogeneous disease with respect to clinical and pathological features and the ultimate outcome. This heterogeneity has defied all the attempts to develop a consensus classification, optimize its management and foretell its prognostication, till recent past (1). A concerted effort over 5-year period by a working group comprising of world-renowned nephrologists (from International IgAN Network) and nephropathologists (from Renal Pathology Society) with special interest in the disease led to the promulgation of the Oxford classification of IgAN in 2009 (2,3). A unique approach was adopted to develop this evidencebased classification. However, the original study cohort that included 265 biopsies was not diverse enough to include all the lesions, which can be seen in IgAN, such as crescents. There were certain other limitations too, such as lack of incorporation of immunofluorescence and electron microscopic data in the development of classification. Ethnic composition was also restricted and comprised of European Caucasians (from North America and Europe) and East Asian (from Japan and China) populations only.
These limitations of the study population were reflected in certain deficiencies in the classification. Some lesions were not studied or analyzed in detail for their prognostic value in the original cohort because of rarity of the lesions or exclusion of such cases from the study cohort (1). The original Oxford classification proposed to focus on four variables in reporting of renal biopsies of patients with IgAN: mesangial hypercellularity (M), endocapillary hypercellularity (E), segmental sclerosis (S), and interstitial fibrosis/tubular atrophy $(\mathrm{T})$. These features were popularly known as MEST scores and Oxford classification is also called the MEST classification.

Due to the above mentioned limitations in the original study cohort, Oxford classification was not meant to be the end classification and the proponents of the classification were cognizant of this fact. The classification was supposed to evolve with time as more data accumulates and more studies are carried out for validation in different parts of the world. In fact, many studies since 2009 have validated the reproducibility and clinical utility of the classification throughout the world (4-15). The classification has also been validated in broader cohorts of patients involving other ethnic groups and the original cohort of the Oxford classification has also been expanded to nearly 
5000 patients by continued international collaborative efforts of the Oxford classification Working Group (1620). The lesions previously not addressed in the original version of the classification have also been studied in these larger cohorts (19-23). The original Working Group is still active, albeit with some change in membership, collaborating with more people from across the world and fully cognizant of the advancements and evidence in this area and is continuously striving to fine tune and enhance the performance of the classification. Working subgroups have been formulated to address problematic areas in the classification (1).

The activity and collaborative efforts of the Working Group have reached fruition recently and an updated version of the classification has been published (1). In this report, there is no change in the adequacy criteria of biopsy. The four key MEST scores also remain unaltered and their clinical utility corroborated. However, some problems in the interobserver variability have been addressed by an online educational material to educate the local pathologists. This has to be complemented. The Working Group is requested to make it freely available to all those interested in it. The main changes recommended in the classification and for which sufficient evidence is available now include: incorporation of crescents (C) score to all cases of IgAN to indicate the frequency of cellular and/or fibrocellular crescents as C0 (no crescents), C1 (crescents in 1 to $24 \%$ glomeruli) or C2 (cresents in $\geq 25 \%$ glomeruli), subdivision of the $\mathrm{S}$ lesion (podocytopathic or nonpodocytopathic in origin) and integration of the clinical data at the time of biopsy with MEST classification to further enhance the prognostic power of the classification. As a result, the classification now includes 5 instead of 4 pathological parameters, i.e., MEST-C score (1).

The activity and collaborative efforts of the Working Group have also led to assembly of a large international cohort of IgAN from multiple centers of the world. The objective is to develop a cohort representing the full spectrum of disease severity in IgAN with no limitations on proteinuria or renal function. This cohort will be a powerful substrate for future research studies on IgAN for refining and improving outcome prediction in individual patients and for refining recruitment and outcome criteria in clinical trials $(1,24)$. Another area of future research focus is the identification of a biomarker or a panel of markers for the non-invasive diagnosis, therapy selection, therapeutic monitoring and prognostication of $\operatorname{IgAN}$. However, efforts in this area have not reached fruition. With rapid advances in the field of "omics" technologies, this dream may be realized in near future. Variable collection and storage of biological samples for biomarker studies represents one important confounding factor in this area. It is anticipated that recommendations will be agreed on and published, based on the large international IgAN cohort, that cover the collection, storage, and transport of biological specimens for biomarker analysis $(1,24)$.
In summary, Oxford classification of $\operatorname{IgAN}$ represents a significant and novel development in the pathological classification of renal diseases, and it continues to evolve as new data and evidence emerges. Continuing efforts of IgAN classification group will pave way for advancements in understanding the pathogenesis, pathology, treatment and outcome of IgAN patients.

Author's contribution

$\mathrm{MM}$ is the single author of the paper.

\section{Conflicts of interest}

The author declares no conflict of interest.

\section{Ethical considerations}

Ethical issues (including plagiarism, data fabrication, double publication) have been completely observed by the author.

Funding/Support

None.

\section{References}

1. Trimarchi H, Barratt J, Cattran DC, Cook HT, Coppo R, Haas M, et al. Oxford Classification of IgA nephropathy 2016: an update from the IgA Nephropathy Classification Working Group. Kidney Int. 2017;91:1014-21.

2. Roberts IS, Cook HT, Troyanov S, Alpers CE, Amore A, Barratt J, et al. The Oxford classification of IgA nephropathy: pathology definitions, correlations, and reproducibility. Kidney Int. 2009;76:546-56.

3. Cattran DC, Coppo R, Cook HT, Feehally J, Roberts IS, Troyanov S, et al. The Oxford classification of IgA nephropathy: rationale, clinicopathological correlations, and classification. Kidney Int. 2009;76:534-45.

4. Kim CH, Lim BJ, Bae YS, Kwon YE, Kim YL, Nam KH, et al.Working Group of International IgA Nephropathy Network and Renal Pathology Society. Immunostaining findings in $\operatorname{IgA}$ nephropathy: correlation with histology and clinical outcome in the Oxford classification patient cohort. Nephrol Dial Transplant. 2011;26:2533-6.

5. Katafuchi R, Ninomiya T, Nagata M, Mitsuiki K, Hirakata H. Validation study of oxford classification of IgA nephropathy: The significance of extracapillary proliferation. Clin J Am Soc Nephrol. 2011;6:2806-13.

6. Herzenberg AM, Fogo AB, Reich HN, Troyanov S, Bavbek $\mathrm{N}$, Massat AE, et al. Validation of the Oxford classification of IgA nephropathy. Kidney Int. 2011;80:310-7.

7. Shi SF, Wang SX, Jiang L, Lv JC, Liu LJ, Chen YQ, et al. Pathologic predictors of renal outcome and therapeutic efficacy in IgA nephropathy: validation of the oxford classification. Clin J Am Soc Nephrol. 2011;6:2175-84.

8. Alamartine E, Sauron C, Laurent B, Sury A, Seffert A, Mariat C. The use of the Oxford classification of IgA nephropathy to predict renal survival. Clin J Am Soc Nephrol. 2011;6:2384-8.

9. Shima Y, Nakanishi K, Hama T, Mukaiyama H, Togawa H, Hashimura Y, et al. Validity of the Oxford classification of IgA nephropathy in children. Pediatr Nephrol. 2012;27:78392.

10. Le W, Zeng CH, Liu Z, Liu D, Yang Q, Lin RX, et al. Validation 
of the Oxford classification of IgA nephropathy for pediatric patientsfrom China.BMCNephrol.2012;13:158.

11. Lee H, Yi SH, Seo MS, Hyun JN, Jeon JS, Noh H, et al. Validation of the Oxford classification of IgA nephropathy: a single-center study in Korean adults. Korean J Intern Med. 2012;27:293-300.

12. Zeng CH, Le W, Ni Z, Zhang M, Miao L, Luo P, et al. A multicenter application and evaluation of the Oxford classification of IgA nephropathy in adult Chinese patients. Am J Kidney Dis. 2012;60:812-20.

13. Kang SH, Choi SR, Park HS, Lee JY, Sun IO, Hwang HS, et al. The Oxford classification as a predictor of prognosis in patients with IgA nephropathy. Nephrol Dial Transplant. 2012;27:252-8.

14. Gutiérrez E, Zamora I, Ballarín JA, Arce Y, Jiménez S, Quereda C, et al. Long-term outcomes of IgA nephropathy presenting with minimal or no proteinuria. J Am Soc Nephrol. 2012;23:1753-60.

15. Lv J, Shi S, Xu D, Zhang H, Troyanov S, Cattran DC, et al. Evaluation of the Oxford Classification of IgA nephropathy: a systematic review and meta-analysis. Am J Kidney Dis. 2013;62:891-9.

16. Nasri H, Mortazavi M, Ghorbani A, Shahbazian H, Kheiri $\mathrm{S}$, Baradaran A, et al. Oxford-MEST classification in IgA nephropathy patients: a report from Iran. J Nephropathol. 2012;1:31-42.

17. Coppo R, Troyanov S, Bellur S, Cattran D, Cook HT, Feehally J, et al. Validation of the Oxford classification of
IgA nephropathy in cohorts with different presentations and treatments. Kidney Int. 2014;86:828-836.

18. Chakera A, MacEwen C, Bellur SS, Chompuk LO, Lunn D, Roberts ISD. Prognostic value of endocapillary hypercellularity in IgA nephropathy patients with no immunosuppression. J Nephrol. 2016;29:367-75.

19. Bellur SS, Lepeytre F, Vorobyeva O, Troyanov S, Cook HT, Roberts IS. Evidence from the Oxford Classification cohort supports the clinical value of subclassification of focal segmental glomerulosclerosis in IgA nephropathy. Kidney Int. 2017;91:235-241.

20. Nasri H, Mubarak M. Focal segmental glomerulosclerosis in IgA nephropathy with regard to Oxford classification: Does it matter? Port J Nephrol Hypert. 2014;28:210-8.

21. Haas M, Verhave JC, Liu ZH, Alpers CE, Barratt J, Becker JU, et al. A Multicenter study of the predictive value of crescents in IgA nephropathy. J Am Soc Nephrol. 2017;28:691-701.

22. Zhang W, Zhou Q, Hong L, Chen W, Yang S, Yang Q, et al. Clinical outcomes of IgA nephropathy patients with different proportions of crescents. Medicine (Baltimore). 2017;96:e6190.

23. Barbour SJ, Espino-Hernandez G, Reich HN, Coppo R, Roberts IS, Feehally J, et al. The MEST score provides earlier risk prediction in IgA nephropathy. Kidney Int. 2016;89:167-75.

24. Coppo R. Biomarkers and targeted new therapies for IgA nephropathy. Pediatr Nephrol. 2017;32:725-31.

Copyright @ 2018 The Author(s); Published by Nickan Research Institute. This is an open-access article distributed under the terms of the Creative Commons Attribution License (http://creativecommons.org/licenses/by/4.0), which permits unrestricted use, distribution, and reproduction in any medium, provided the original work is properly cited. 